\section{Anthracycline cardiotoxicity and acute myelogenous leukaemia}

The cardiotoxicity of the anthracycline antibiotic daunorubicin (DNR) and its 14-hydroxylated analogue Doxorubicin (DXR) limits their use in cancer treatment. ${ }^{1}$ The cardiotoxicity manifests itself as sudden heart failure which may progress rapidly to death. ${ }^{2}$ The most frequent electrocardiographic abnormality is low voltage of the QRS complex, but monitoring the ECG does not appear to be helpful in predicting toxicity, ${ }^{3}$ and this was so in our patients who all received a total dose of more than the recommended maximum of $550 \mathrm{mg} / \mathrm{m}^{2}{ }^{4}$

\section{Patients, methods, and results}

Twenty patients with acute myeloblastic leukaemia (AML) who received DNR or DXR, or both, in a total dose of more than $550 \mathrm{mg} / \mathrm{m}^{2}$ were studied (table). All patients except one had no evidence of cardiac disease before treatment. Eighteen patients had received repeated induction courses consisting of single injections of DNR $(1.5 \mathrm{mg} / \mathrm{kg})$ and cytosine arabinoside (CA) (1 mg/kg intravenously 12-hourly for five days). Two patients had had their first induction with CA and thioguanine, but required the anthracycline drugs for reinduction when they relapsed. Patients were then randomised to receive either maintenance chemotherapy alone or chemotherapy together with immunotherapy. Nine patients had chemotherapy only as maintenance, while eleven patients had additional immunotherapy. Maintenance chemotherapy was given every four weeks and consisted of a single dose of DNR $(1.5 \mathrm{mg} / \mathrm{kg})$ or DXR (1 mg/kg intravenously) and CA $(1 \mathrm{mg} / \mathrm{kg})$ given intravenously in normal saline over eight hours. Immunotherapy with intravenous BCG (Glaxo Ltd) was given 14 days after the completion of maintenance chemotherapy and alternating with chemotherapy every two weeks. ${ }^{5}$ Patients who were still in remission after receiving a total dose of anthracycline antibiotics of $550 \mathrm{mg} / \mathrm{m}^{2}$ were transferred to CA and thioguanine. Patients who had relapsed usually received re-induction treatmen with anthracycline antibiotics and CA. All patients had their chest $x$-ray examination and ECG carefully assessed before each anthracycline infusion.

Of the 20 patients in the study, only two developed cardiomyopathy. The first patient (patient 12, table) received a total dose of $1006 \mathrm{mg} / \mathrm{m}^{2}$ of the anthracycline antibiotics (709 $\mathrm{mg} / \mathrm{m}^{2}$ of DNR and $297 \mathrm{mg} / \mathrm{m}^{2}$ of DXR), the last dose of DXR about six weeks before the onset of heart failure. Congestive heart failure developed rapidly, with the sudden onset of breathlessness and ankle oedema. A third heart sound was easily heard and the chest $x$-ray film showed a large heart. The ECG, which was normal initially, now showed low voltage complexes with flattened and inverted T-waves. Prompt treatment with digoxin and diuretics reversed her congestive cardiac failure and she again became ambuiant without symptoms.

The second patient (patient 14 , table), received a total dose of $825.8 \mathrm{mg} / \mathrm{m}^{2}$ of DNR, the last dose two weeks before symptoms of heart failure developed. Chest $x$-ray examination showed an enlarged heart with evidence of pulmonary oedema and bilateral pleural effusions. The ECG showed low voltage in the frontal plane leads with flattened $T$-waves in these leads and in the lateral precordial leads. She responded to anti-heart-failure measures and the ECG changes disappeared. The patient died 15 weeks later with a relapse of her acute leukaemia. In both patients there had been no changes on the chest $x$-ray film or ECG before heart failure was clinically evident.

One patient (patient 20, table) had had a posterior myocardial infarct two years previously. He suffered no unexpected side effects from treatment, his ECG was unchanged throughout, and subsequent post-mortem examination showed an old posterior myocardial infarct. Repeated chest $x$-ray films and ECGs in the remaining 17 patients were normal throughout.

\section{Discussion}

Most patients were given DNR initially, changing later to DXR (see table), and the recommended total dose was exceeded because many patients with AML in relapse had become resistant to other cytotoxic drugs. Only two of our patients developed heart failure: predictably the two who received the largest total doses. Furthermore, both responded to anti-failure treatment and in neither patient was heart failure the cause of death.

In view of the low incidence of DXR/DNR congestive cardiac failure in our patients $(9 \%)$, and of the satisfactory response to treatment, we consider that these drugs should not be withheld from patients who have malignant disease with a poor prognosis and who have become resistant to other cytotoxic agents, but who have already received the maximum recommended total dose. The potential benefit in terms of further remission outweighs the risk of toxicity. Other reports have suggested that congestive heart failure may be controlled in children, particularly if diagnosed early, ${ }^{2}$ and our experience has shown that this is also possible in adults. We would therefore recommend reintroduction of anthracycline drugs for these patients while being aware of the increased risk of heart failure.

1 Benjamin, R S, Weirnik, P H, and Bachur, N R, Cancer, 1974, 33, 19.

2 Praga, C, et al, Adriamycin Review. Ghent, European Press Medikon, 1975.

3 Le Frak, et al, Cancer, 1973, 32, 302.

${ }^{4}$ Blum, R H, and Carter, S, Annals of Internal Medicine, 1974, 80, 249.

5 Whittaker, J A, and Slater, A, British fournal of Haematology, 1977, 35, 263.

(Accepted 7 February 1977)

Department of Haematology, University Hospital of Wales and

Welsh National School of Medicine, Cardiff CF4 4XW

S A D AL-ISMAIL, MB, MRCP, senior house officer

D H PARRY, $M B, C H B$, lecturer

J A WHITTAKER, MD, MRCP, senior lecturer

\section{Successful treatment of longstanding biliary atresia}

Biliary atresia is generally believed to have a poor prognosis, untreated patients usually surviving only one to two years. ${ }^{1}$ Even when surgery is technically possible there is a high mortality from operation, ascending cholangitis, and the effects of secondary biliary cirrhosis.

We describe a patient with remarkably longstanding biliary atresia who obtained benefit from surgery at the age of 19 years.

\section{Case report}

The patient, aged 19, was born at home after an uncomplicated pregnancy. At 5 months he underwent laparotomy for obstructive jaundice. The hepatic

Doxorubicin and daunorubicin dosage details in 20 patients receiving a total dosage of over $550 \mathrm{mg} / \mathrm{m}^{2}$

\begin{tabular}{|c|c|c|c|c|c|c|c|c|}
\hline Patient & Age & Sex & $\begin{array}{c}\text { Surface } \\
\text { Area } \\
\left(\mathrm{m}^{2}\right)\end{array}$ & $\begin{array}{l}\text { Total dose of } \\
\text { DNR } \\
(\mathrm{mg})\end{array}$ & $\begin{array}{c}\text { Total dose of } \\
\text { DXR } \\
\text { (mg) }\end{array}$ & $\begin{array}{c}\text { Dose of } \\
\text { DNR/m² } \\
(\mathrm{mg})\end{array}$ & $\begin{array}{c}\text { Dose of } \\
\text { DXR/m } \\
(\mathrm{mg})\end{array}$ & $\begin{array}{c}\text { Total dose of } \\
\mathrm{DNR}+\mathrm{DXR} / \mathrm{m}^{2} \\
(\mathrm{mg})\end{array}$ \\
\hline $\begin{array}{r}1 \\
2 \\
3 \\
4 \\
5 \\
6 \\
7 \\
8 \\
9 \\
10 \\
11 \\
12 \\
13 \\
14 \\
15 \\
16 \\
17 \\
18 \\
19 \\
20\end{array}$ & $\begin{array}{l}20 \\
63 \\
27 \\
58 \\
40 \\
60 \\
73 \\
21 \\
44 \\
64 \\
42 \\
56 \\
35 \\
27 \\
44 \\
69 \\
45 \\
59 \\
40 \\
58\end{array}$ & $\begin{array}{l}M \\
M \\
F \\
M \\
F \\
M \\
M \\
M \\
M \\
F \\
F \\
F \\
F \\
F \\
F \\
F \\
M \\
M \\
M \\
F \\
M\end{array}$ & $\begin{array}{l}1.6 \\
1.65 \\
1.4 \\
2.45 \\
1.55 \\
1.72 \\
1.75 \\
1.7 \\
2.5 \\
1.5 \\
1.63 \\
1.65 \\
1.48 \\
1.55 \\
1.75 \\
1.65 \\
1.7 \\
1.6 \\
1.5 \\
1.75\end{array}$ & $\begin{array}{r}610 \\
640 \\
560 \\
1120 \\
635 \\
810 \\
740 \\
870 \\
960 \\
600 \\
1100 \\
1170 \\
1000 \\
1280 \\
930 \\
900 \\
630 \\
710 \\
1000 \\
610\end{array}$ & $\begin{array}{l}520 \\
390 \\
330 \\
370 \\
350 \\
540 \\
410 \\
680 \\
390 \\
360 \\
490 \\
135 \\
50 \\
380 \\
480 \\
520 \\
440\end{array}$ & $\begin{array}{l}381 \cdot 25 \\
387 \cdot 87 \\
400 \\
560 \\
409 \cdot 67 \\
470 \cdot 93 \\
422 \cdot 85 \\
511.76 \\
480 \\
400 \\
674 \cdot 8 \\
709 \\
675 \cdot 67 \\
825 \cdot 8 \\
531 \cdot 42 \\
545 \cdot 4 \\
370 \cdot 58 \\
443 \cdot 7 \\
666 \\
398 \cdot 5\end{array}$ & $\begin{array}{l}325 \\
236 \cdot 36 \\
235 \cdot 71 \\
185 \\
225 \cdot 80 \\
313 \cdot 95 \\
234 \cdot 28 \\
400 \\
195 \\
240 \\
297 \\
91 \cdot 21 \\
28 \cdot 57 \\
230 \cdot 3 \\
282 \cdot 35 \\
325- \\
251 \cdot 4\end{array}$ & $\begin{array}{c}706 \cdot 25 \\
624 \cdot 24 \\
635 \cdot 71 \\
745 \\
635 \cdot 47 \\
784.88 \\
657 \cdot 03 \\
911 \cdot 76 \\
675 \\
640 \\
674 \cdot 8 \\
1006 \\
766 \cdot 88 \\
825 \cdot 8 \\
560 \\
775 \cdot 7 \\
652 \cdot 9 \\
768 \cdot 7 \\
666 \\
600\end{array}$ \\
\hline
\end{tabular}


cystic, and common bile ducts were described as "solid cords with a very small possible lumen, from which a tiny drop of bile was obtained. The ducts could not be dilated and the common bile duct appeared to end in a faint cord. The gall-bladder was smooth and shrunken." No further procedure was undertaken and his recovery was satisfactory, though he developed a biliary fistula, which closed spontaneously.

Subsequently the patient had an extensive medical history. He underwent mastoidectomy after otitis media and later developed maxillary osteomyelitis, which resolved with antibiotic treatment. When aged 3 his right eye was destroyed by an inflammatory mass. At 11 he developed inflammatory changes in the left eye. Despite treatment his sight was lost. He then fractured his skull in a road accident and underwent craniotomy for an extradural haematoma. In his early teens he suffered from spinal osteochondritis (Scheuermann's disease).

Though he maintained normal growth and development, he had persistent hepatosplenomegaly and abnormal liver function values. Itching became a great problem, which was not relieved by phenobarbitone prescribed for grand-mal convulsions after his craniotomy. In 1972 he developed xanthelasmata. His plasma cholesterol was $8.5 \mathrm{mmol} / 1(328 \mathrm{mg} / 100 \mathrm{ml})$ and triglyceride $0.72 \mathrm{mmol} / \mathrm{l}(64 \mathrm{mg} / 100 \mathrm{ml})$, and prominent alpha and beta bands were found on electrophoresis. He began treatment with cholestyramine with improvement of the xanthelasmata, itching, and blood lipid concentrations.

In 1975 he was complaining bitterly of itching and was unable to tolerate cholestyramine regularly. He had xanthelasmata and hepatosplenomegaly. Liver function values were: total bilirubin $22 \mu \mathrm{mol} / 1(1.3 \mathrm{mg} / 100 \mathrm{ml})$, aspartate transaminase $78 \mathrm{U} / 1$, alkaline phosphatase $31 \mathrm{KAU}$, albumin $44 \mathrm{~g} / \mathrm{l}$, globulin $34 \mathrm{~g} / \mathrm{l}$, and cholesterol $5.5 \mathrm{mmol} / \mathrm{l}(212 \mathrm{mg} / 100 \mathrm{ml})$. His serum was negative for hepatitis $B$ antigen and gave negative or insignificant titres against routine antiviral, toxoplasma, and toxocaral antibodies. Intravenous cholangiography showed a good concentration of dye in the gall bladder.

In view of this and the pruritus a second laparotomy was performed. The operative cholangiogram (see figure) showed uniform narrowing of the ducts. Cholecystojejunostomy was performed. The liver was cirrhotic.

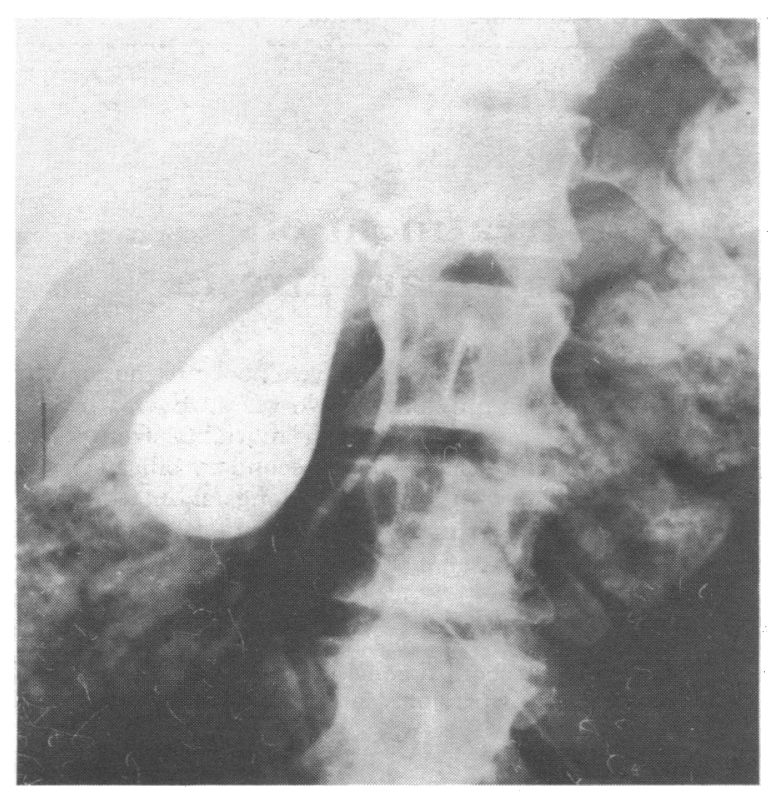

Operative cholangiogram showing uniformly narrowed common bile duct.

His progress was excellent, with complete loss of itching and a substantial fall in total bilirubin. Four months after operation the total bilirubin was $14 \mu \mathrm{mol} / 1(0.8 \mathrm{mg} / 100 \mathrm{ml})$, aspartate transaminase $81 \mathrm{U} / 1$, alkaline phosphatase $26 \mathrm{KAU}$, cholesterol $6.5 \mathrm{mmol} / 1(250 \mathrm{mg} / 100 \mathrm{ml})$, and triglyceride $0.70 \mathrm{mmol} / \mathrm{l}(62 \mathrm{mg} / 100 \mathrm{ml})$. He remained symptom free one year after operation.

\section{Comment}

Prolonged survival of patients with biliary atresia is unusual, though spontaneous reversal may occur. ${ }^{2} 3$ Krovet $^{3}$ described a patient surviving to 16 years, and she too had suffered pruritus and xanthelasmata. Recent views ${ }^{4}$ of biliary atresia as an inflammatory event, which may resolve like neonatal hepatitis, may explain such survival. The relation of biliary atresia to our patient's other illnesses is not clear.
The disappearance of itching after operation was gratifying. The fall in postoperative bilirubin levels suggests that, though there had been no complete obstruction, impedence to bile flow was much reduced. Neither cholestyramine nor phenobarbitone had completely relieved his pruritus. Though cirrhotic changes may regress after operation in infancy, ${ }^{5}$ our patient's prognosis must be guarded.

1 Hays, D, and Snyder, W, Surgery, 1963, 54, 373.

2 Holder, T, American fournal of Surgery, 1964, 107, 458.

3 Krovetz, J, Surgery, 1960, 47, 453.

${ }^{4}$ Hays, D, Surgical Clinics of North America, 1973, 53, 1257.

5 Thaler, M, and Gellis, S, American fournal of Diseases of Children, 1968, 116, 271 .

(Accepted 5 fanuary 1977)

University of Southampton, Southampton SO9 4PE

K J FOSTER, MB, MRCP, research fellow

$S$ J KARRAN, MB, FRCS, senior lecturer in surgery

\section{Hypernephroma in two brothers}

Hypernephroma (Grawitz tumour or adenocarcinoma of the kidney) is a relatively common tumour. Unlike tumours of the breast, stomach, or endometrium-which commonly show a familial pattern-hypernephroma has been reported in close relations only infrequently. This report concerns two brothers who came under our care.

\section{Case reports}

Case 1-A 53-year-old man was first seen in March 1974 with bilateral inguinal herniae and rectal bleeding. The findings on sigmoidoscopy and barium enema were normal. His piles were injected and the herniae repaired. He returned with further rectal bleeding in December 1974 and routine examination showed a large tumour mass in the region of the left kidney. Intravenous pyelogram showed expansion of the lower pole of the left kidney with distortion of the middle and lower calyces, consistent with a diagnosis of a renal tumour. At operation an $11-\mathrm{cm}$ diameter hypernephroma was removed and the patient made an uneventful recovery. Postoperatively he complained of backache and pain down the left leg-symptoms which he had had for many years.

In September 1975, $x$-ray films of the lumbar spine and left leg were normal. Two months later he was injured in a road traffic accident and sustained a subcapital fracture of the left femur. Nevertheless, an $x$-ray film showed that the fracture had taken place through a metastasis and hip replacement was performed. At operation the upper end of the femur was infiltrated with tumour, which proved to be secondary hypernephroma. Pain in the region persisted postoperatively and he was given radiotherapy to the full level of tissue tolerance, 4125 rads in a 3-week period. His condition gradually deteriorated, and he died on 27 July 1976, 24 hours after his brother.

Case 2-A 59-year-old man first presented in November 1975 with rectal bleeding. Sigmoidoscopy and proctoscopy showed piles which were treated by injection. Two months later he developed severe pain in the area of the left kidney and a mass was felt in the left hypochondrium. Intravenous pyelogram showed an extensive tumour affecting the upper pole of the left kidney. Chest $x$-ray examination showed a secondary deposit in the right lung, and suspicious areas were noted in the ribs and lumbar spine on bone scan. At operation in February 1976 the mass was found to be infiltrating extensively into the surrounding structure, making removal impossible. Biopsy disclosed a hypernephroma. He was subsequently referred for radiotherapy and received 4125 rads over a period of three weeks. He gradually deteriorated and died on 26 July 1976.

\section{Discussion}

Clemmesen ${ }^{1}$ reported a remarkable family of 15 siblings of whom two had hypernephromas and six had polycystic kidneys. Brinton ${ }^{2}$ treated a family in which three siblings had hypernephromas confirmed and the father had been treated for a renal tumour but this had not been confirmed histologically. Steinberg et al ${ }^{3}$ reported the same tumour in a mother and daughter and cited six further case reports in three pairs of siblings. A remarkable family of five siblings was reported by Franksson et $a l^{4}$ in which four siblings had multiple bilateral tumours and a further sibling had a solitary tumour in one kidney. Thus, if the parent in Brinton's cases is included, there have 